\title{
PERFORMANCE EFFECTIVENESS OF CASSAVA FLOUR PROCESSING MACHINE FOR SMALL-MEDIUM INDUSTRIES
}

\author{
EMANUEL ALEXANDER RETTOB ${ }^{1}$, ZULKIFLI DJAFAR ${ }^{2}$ \& HAMMADA ABBAS ${ }^{3}$ \\ ${ }^{1}$ Politeknik Amamapare Timika, Mimika, Papua, Indonesia \\ ${ }^{2,3}$ Mechanical Engineering Department, Faculty of Engineering, Hasanuddin University Makassar
}

South Sulawesi Province, Indonesia

ABSTRACT
Cassava is one of the favorite foods in Indonesia. Tual and Southeast Maluku Province are the regions with cassava as
their staple food since the ancient time, which in local language it is called "embal". The processing of cassava into
traditional foods is still performed manually which in its process includes: peeling, cleaning, slice, and dried with
squeezing step to release the water content, and then sieved by using a plaited bamboo sieve. Manual processing is far
from economic because it requires plenty of time and energy. This research aims to find out the performance
effectiveness of cassava processing machine for small and medium industries. This research used an engineering
method by designing the cassava processing machine. This machine has three main parts: 1$)$ Screw conveyor with a $1 / 2$
HP motor with 1430 rpm torque, to reduce the gearbox torque (type 60 ) with the ratio of 1:50, 2) Grinder, FFC 23 mesh
0.5 type with 3 HP and 2300 rpm motor, 3 ) Sieve with $3 / 4$ HP and 1430 rpm motor to reduce the gearbox (type 60$)$
torque with a ratio of $1: 30$. The produced capacity by the cassava processing machine is 30 kg/hour.
KEYWORDS: Cassava, Flour Processing Machine Performance \& Machine Built-up Design

Received: Jun 08, 2020; Accepted: Jun 28, 2020; Published: Sep 01, 2020; Paper Id.: IJMPERDJUN20201002

\section{INTRODUCTION}

Cassava is one of Indonesia's local carbohydrate sources which is the third-largest after rice and maize. This plant has the potential to be processed into flour [1]. In general, cassava fruit is white and cannot be directly consumed because fresh cassava contains cyanide which is very toxic to humans and animals. Therefore it needs to be processed to reduce the cyanide content to a safe level [2]. Currently, the processing of cassava in Southeast Maluku and Tual City is performed manually. The cassava is shredded manually by hands and slice using slicer equipment. Sliced cassava is then put into the sack, and on top, it is given a weight in the form of stone as a ballast material. After that, it is sieved into the flour with a sieve made of bamboo. For efficiency and economic reasons, better processing machine is required [3]. The research method used is the engineering method [4]. The research objective is implied by the manufacture of cassava flour processing machine that has a strong construction, adequate and efficient facilities to facilitate operation and produce quality flour. The type of conveyor can be selected based on the suitability of the fulfilment of the raw material requirements by the characteristics of a conveyor, the score calculation is carried out through the weighted evaluation method and the expected value criteria [5]. There are some researches related to cassava flour processing machines reported that the transfer process from one stage to another using material equipment is designed in such a way as to facilitate the loading process by human hands. For example, a conveyor system that can be used to facilitate the transportation of material [6]. Where the choice of a conveyor or other moving equipment is affected by the type of material being transferred. The capacity required in a 
certain time, direction and length of transfer as well as economic value factors are also necessary for selecting material equipment [7]. The process of milling agricultural products is one of the oldest human cultural engineering processes. As a reduction in size, processing and storage the farmers are forced to develop technology to grind their products [8]. In the design of the sieving device, it was found that a tool to separate unused minerals was used a sand sieving machine with a motor power of $1.5 \mathrm{HP}$ with a rotation of $1,400 \mathrm{rpm}$ to reduce rotation, a gearbox reducer type 60 was used, the screen movement was transmitting back and forth connected to the crankshaft, the resulting capacity of $500 \mathrm{~kg} / \mathrm{hour}$ sand sieving machine, [9].In previous studies, the design of cassava flour making equipment greatly affects the level of comfort for operators when operating [10]. Because with the machine, the agricultural products of cassava flour, which are the staple food of the community can be processed quickly using machine power and in a short time. The remaining moisture content in the process of drying the chopped cassava with sunlight, the residual moisture content generally ranges from $12-15 \%$ to produce tapioca flour with a lower level of dryness than oven drying machines [11]. The degree of fineness of tapioca flour that is processed manually will usually be coarse due to the use of an unsuitable sieve and size. Mesh is the number of holes in 1 linear inch; the standard of flour fineness is $0.09 \mathrm{~mm}$ with the sieve material used is made of stainless steel. With the data and conditions in the field, we try to design and build a simple cassava flour processing machine so that it can streamline time and energy in processing cassava flour, which still uses manual processes.

\section{RESEARCH METHOD}

\section{Tools and Materials}

The tools used in the manufacture of cassava flour processing machine are cutting grinder machine, hand-handled grinder, and hand-handled drilling machine, 120-ampere welding machine, lathe, hand-handled saw, 30-cm meter, elbow tool $45^{\circ}$, plate scissor, hammer, wire brush, calliper, and ruler. The raw materials used in the testing of the cassava flour processing machine is cassava with harvesting age of 7-8 months. The used cassava fermentation preservative is stater Bimo CV.

\section{Materials Used in the Construction of Flour Processing Machine}

The making of the frame of cassava flour processing machine included: The making of conveyor frame, grinder frame, and sieve frame, which were made of C- grade steel sized $2 \mathrm{~cm} \times 2 \mathrm{~cm} \times 8 \mathrm{~cm}$, with $3 \mathrm{~mm}$ thickness, using material S $45 \mathrm{C}$, the aluminium plate with $1 \mathrm{~mm}$ and $0.5 \mathrm{~mm}$ plate thickness. Stainless steel plate with a thickness of $0.5 \mathrm{~mm}$ and $1 \mathrm{~mm}$. The collected data from the designing result were obtained using stopwatch and scale used to measure the water level in wet cassava, dried cassava, and flour.

\section{Designing Method}

The designing method used is the engineering method in the process of designing and building a cassava flour processing machine. With the design, the stage was covering dimensions, including length, width and height. Materials were iron, aluminium, plastic and others. Considered questions included how is the mechanical system of the machine so that cassava fruit can become flour, how are the series of electricity sources and construction used for the flour processing machine and the control method, in other words how the process runs and the process of flour production.

\section{Construction of Cassava Flour Processing Machine Design}

- The design of the cassava flour processing machine is shown in Figure 1 and divided into three main parts:

- Screw Conveyor which consists of a conveyor screw mounting tool frame, screw pipe, screw shaft, bearings, 
electric motor, pulley, fanbelt, sprocket, chain, cassava filling funnel, cassava material outlet funnel and fastening bolt nuts.

- Cassava grinding equipment consists of a frame for a grinder holder, grinder, electric motor, pulley, fanbelt, cassava filling funnel, cassava material outlet funnel and fastening bolts.

- Cassava flour sieve consists of sieve holder frame, sieve, electric motor, pulley, fanbelt, spring, bearing funnel for filling cassava material, sieving frame body, storage tub for cassava flour, cassava material outlet, cassava sieve shaft and bolt nuts fastener

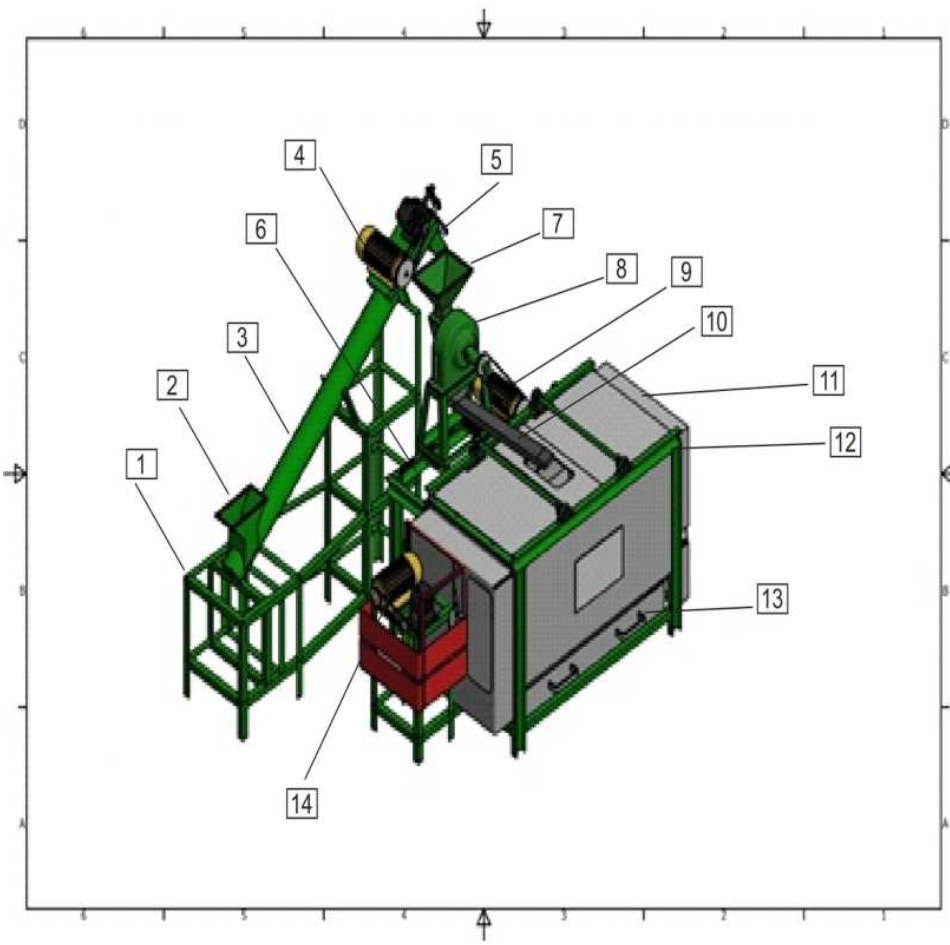

Note:

1. Frame of Conveyor

2. Filling Funnel of Conveyor

3. Pipe of Conveyor

4. Electrical Motor $1 / 2 \mathrm{HP}$

5. Output Funnel of Conveyor

6. Grinding Tool Frame

7. Filling Funnel of Grinder

8. Grinding Unit

9. Electrical Motor $3 \mathrm{HP}$

10. Output Funnel of Grinder

11. Cover of Sieve Frame

12. Frame of Sieving Tool

13. Collecting Vessel

Figure 1: Build-up Design of Cassava Flour Processing Machine.

14. Electrical Motor 3/4 HP

\section{Trial Run Step}

After all, the planning and design stages have been completed, and the next step is testing to evaluate whether the flour processing machine can work following the functions of each part, both from the mechanical and electrical side.

\section{Design Calculation}

Calculation mechanical components include pulley selection, belt length, and the distance between pulley centers, sprocket selection, chain length, and distance between sprocket centers. And calculate the rotational speed of the conveyor (Figure 2.A), the rotational speed of the grinder (figure 2.B), and the rotational speed of the sieve (figure 2.C). 


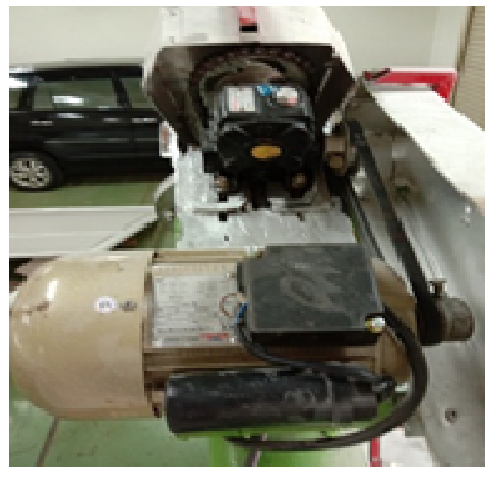

A

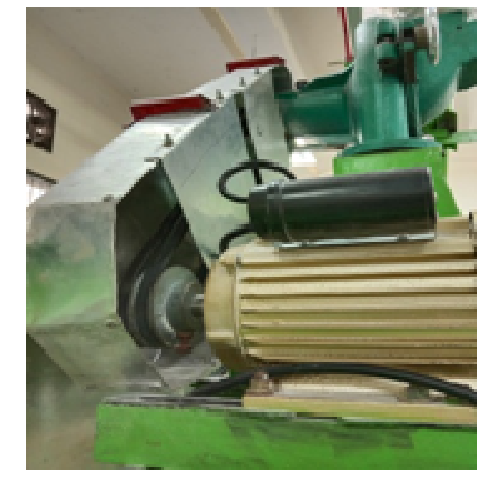

B

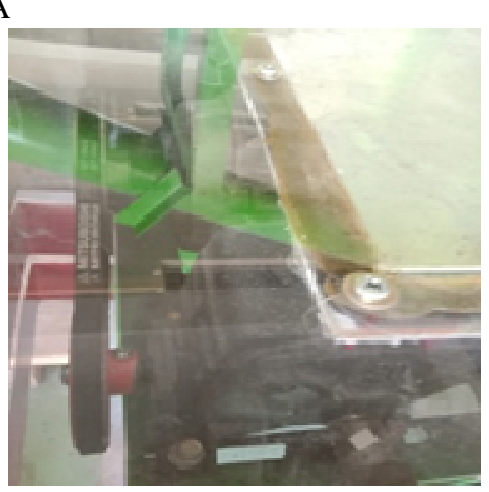

C

Figure 2. (A) Design of the Screw Conveyor Tool Rotation.

(B) The Design of the Grinder Rotation $(C)$ the Design of the Sieve Rotation.

\section{Used Formulas}

- Main components of the designed screw conveyor

- Calculation of machine speed (N2) generated on the conveyor. The speed of the motor that drives the conveyor tool is known (N1) $1430 \mathrm{rpm}[12]$.

- $\quad \mathrm{N} 2=(\mathrm{N} 1 \times 2): 3(1)$

- Calculation of the gear box ratio (N3). The gear box ratio used is: (1:50) data:

- $\quad$ since type gear box = WP A 40 [12].

- $\quad \mathrm{N} 3=(\mathrm{N} 2 \times 1): 50(2)$

- $\quad$ Calculating gear box ratio (N4) [12].

- $\quad \mathrm{N} 4=(\mathrm{N} 3$ X 3$): 1,5(3)$

- Figure 3 is the schematic of belt transmission for screw conveyor, grinder and sieve 


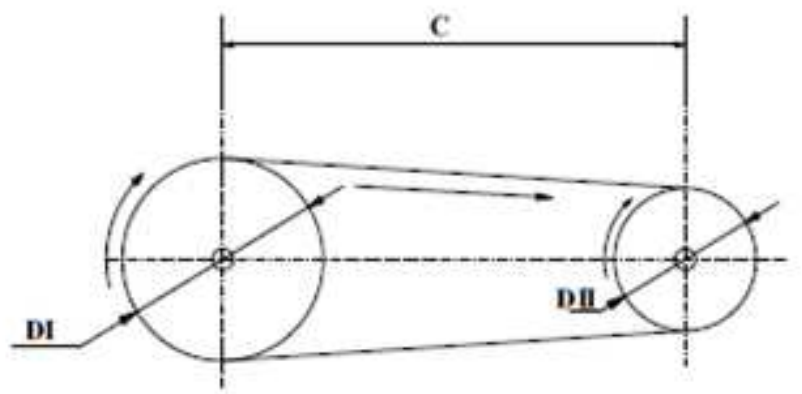

Figure 3: Schematic of Belt Transmission in Screw Conveyor.

- Selection of the appropriate belt.

Selection of the belt type according to the carpet diagram shown in the figure 4 .
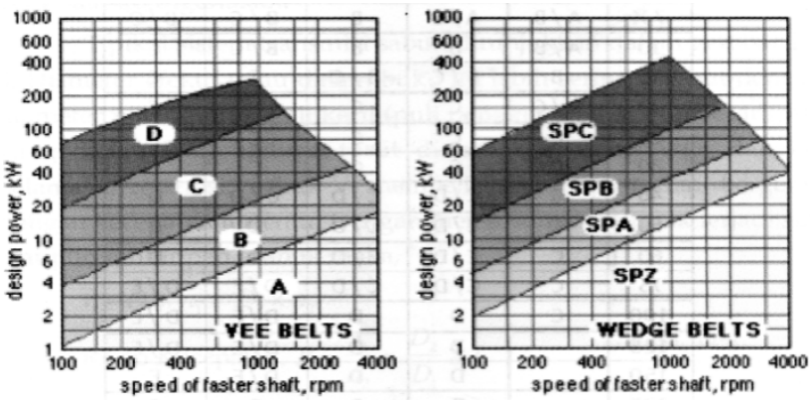

Figure 4: Carpet Diagram [13].

- Calculation of the distance between the pulley centers

So that based on the equation, it can be obtained the distance between the centers of the pulley (c) with the following equation [13].

$$
\mathrm{C}=3(\mathrm{DI}+\mathrm{D} 2)(4)
$$

- Calculating the circumference of the belt.

To obtain the circumference of the belt, the following equation is used [13].

$\mathrm{L}=2 \mathrm{C}+(\mathrm{D} 1+\mathrm{D} 2)(5)$

- Schematic planning of transmission of sprocket, chain on conveyor.

- $\quad$ Determining the size of the sprocket with the following equation. [13].

$\mathrm{D}=\frac{\text { Pitch }}{\sin \left[\frac{180^{0}}{\text { Gear Number }}\right]}$

- Determining the length of the chain and sprocket with the following equation [13].

$$
L=2 c+\frac{N_{2}+N_{1}}{2}+\frac{\left(N_{2}+N_{1}\right)^{2}}{4 \pi^{2} \cdot c}
$$


- Determining the distance between the centers of the sprocket

Distance between the centers of the Cs sprocket is questioned. So based on the following equation [13]:

$$
\mathrm{Cs}=\frac{1}{4}\left[\mathrm{~L}-\frac{\mathrm{N}_{2}+\mathrm{N}_{1}}{2}+\sqrt{\left(\mathrm{L}-\frac{\mathrm{N}_{2}+\mathrm{N}_{1}}{2}\right)^{2}-\frac{8\left(\mathrm{~N}_{2}+\mathrm{N}_{1}\right)^{2}}{4 \pi^{2}}}\right.
$$

- Determining the diameter of the conveyor screw shaft, with the following equation [14].

$$
T=\frac{\pi}{16} T d_{0}^{3}\left(1-\frac{d_{1}}{d_{0}}\right)^{4}
$$

- Main components of designed grinding tool

- Calculating the machine speed (N2) generated on the grinder. Electric motor rotation (N1) $2890 \mathrm{rpm}$, with the following equation. [12].

$\mathrm{N} 2=(\mathrm{N} 1 \times 4): 3$

- Schematic drawing of the belt transmission on the grinder can be seen in Figure 3

- Selection of appropriate belts.

The type of belt is selected based on the power and rotation of the initial drive used and can be obtained from the carpet diagram in Figure 4.

- Calculating distance between the centers of the pulleys, with the following equation [13]. $3(\mathrm{D} 1+\mathrm{D} 2)$

- Calculating the circumference of the belt, with the following equation [13].

$\mathrm{L}=2 \mathrm{C}+(\mathrm{D} 1+\mathrm{D} 2)$

- The main component of the designed sieve

- Calculating the machine speed (N2) generated on the sieve unit. The rotation of the motor driving the sieve (N1) is known as $1430 \mathrm{rpm}$. [12].

$$
\mathrm{N} 2=(\mathrm{N} 1 \times 3): 2
$$

- Calculating gear box ratio. [12].

$\mathrm{N} 3=(\mathrm{N} 2 \times 1): 30$

- Calculating gear box ratio ( N4 ). [12].

$\mathrm{N} 4=(\mathrm{N} 3 \mathrm{X} 4): 1 / 2$

- The schematic image of the belt transmission on the sieving device can be seen in Figure 3

- Selection of appropriate belts. 
The type of belt is selected based on the initial power and rotation used and can be obtained from the carpet diagram in figure 4.

- Calculating distance between pulley centers with the following equation.

$$
3(\mathrm{D} 1+\mathrm{D} 2)
$$

- Calculating the circumference of the belt using the following equation [13].

$$
\mathrm{L}=2 \mathrm{C}+(\mathrm{D} 1+\mathrm{D} 2)
$$

\section{RESULTS AND DISCUSSIONS}

\section{Design of Flour Processing Machine}

This design is more focused on what is stated in general objectives: the effectiveness of the performance of the cassava flour processing machine which includes screw conveyor, grinder and sieve with a capacity of $30 \mathrm{~kg} / \mathrm{hour}$ with excellent results shown in Figure 5. Related researches. The design of cassava tapioca flour producing machine with three steps is implemented in one process series with shorter duration and higher production. The three phases, including grating, squeezing, and sieving, require high energy in one run of processing averagely $5 \mathrm{~kg}$ cassava, which needs $11 \mathrm{minutes}$ processing time. The resulted tapioca flour is minimal, an average of $5 \mathrm{~kg}$ of cassava produce $300-350$ grams because the processed cassava is not fresh or dried so that the cassava starch produced is minimal. [15].
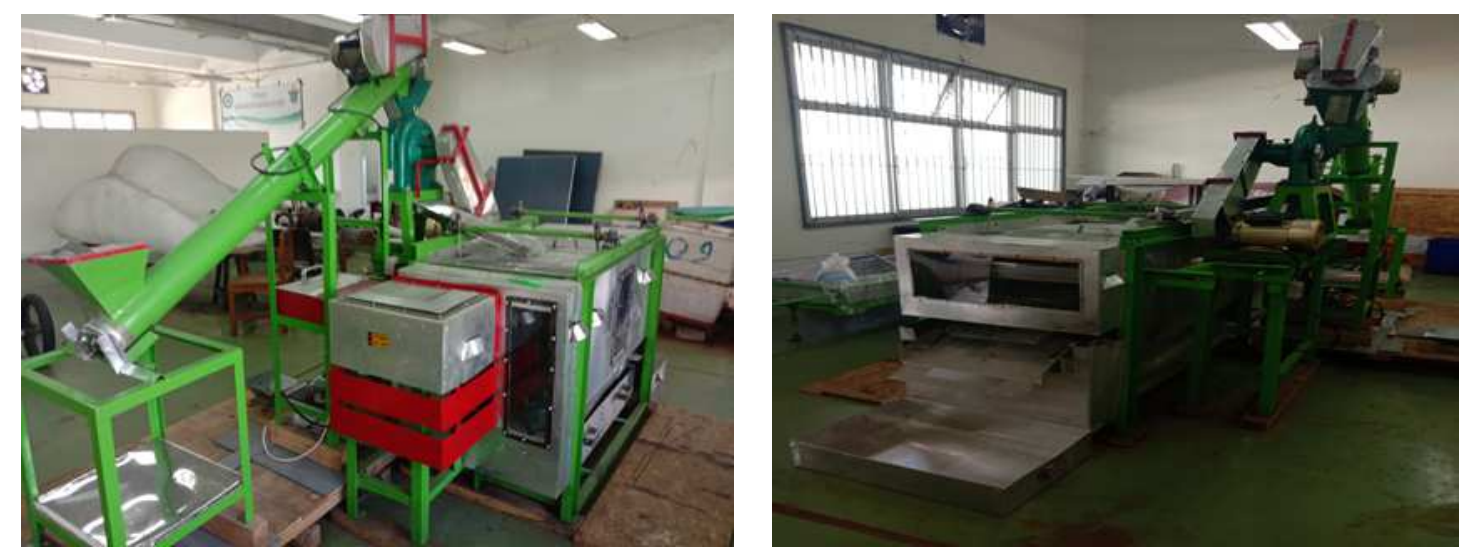

Figure 5: The Result of Designed Cassava Flour Processing Machine.

\section{The Results of the Trial Run of the Cassava Flour Processing Machine}

with the Measurement of each Tool Dimensions are

- Screw conveyor with $\varnothing 5$ inch pipe and 2 meters in length, 1 inch screw conveyor shaft diameter with a $35^{\circ}$ slope of the screw conveyor

- $\quad$ Grinder with FFC 23 size, dimensions 687x429x115 with $0.5 \mathrm{~mm}$ mesh size

- Cassava flour sieve with a length of $1400 \mathrm{~cm}$ x width $7.76 \mathrm{~cm}$ x height $1080 \mathrm{~cm}$ with mesh sieve size 60.

\section{Calculation Data of Cassava Flour Processing Machine Components}

- $\quad$ Screw conveyor holder. Electric motor $=1 / 2 \mathrm{hp}$, rotation N1 = $1430 \mathrm{rpm}, \mathrm{N} 2=953.33 \mathrm{rpm}, \mathrm{N} 3=19.06$, N4 = $47.65 \mathrm{rpm}$, fan belt type A, distance between pulley centers = $15 \mathrm{inch}$, length of belt circumference $=24.47$ inch, 
gear box ratio $=47.65 \mathrm{rpm}$, sprocket size $\varnothing \mathrm{D} 5 \mathrm{inch}, \varnothing \mathrm{d} 2 \mathrm{inch}$, chain length $26 \mathrm{inch}$, distance between sprocket center 20 pitch. Screw conveyor rotating speed $=47.65 \mathrm{rpm}, \varnothing$ screw conveyor shaft $=25 \mathrm{~mm}$

- $\quad$ Grinder holder. Electric motor $=3 \mathrm{hp}$, rotation N1 = $2890 \mathrm{rpm}, \mathrm{N} 2=3853.3 \mathrm{rpm}$, fanbelt type A / B, distance between pulley centers $=21$ inch, length of belt circumference $=56.57$ inch $\emptyset$. the result of the rotating speed of the grinding tool $=3853.33 \mathrm{rpm}$

- $\quad$ Flour sieve. Electric motor = 3/4 hp, N1 rotation = $1430 \mathrm{rpm}, \mathrm{N} 2=2145 \mathrm{rpm}, \mathrm{N} 3=71.5 \mathrm{rpm}, \mathrm{N} 4=143 \mathrm{rpm}$, fan belt type A, distance between pulley centers $=7 \mathrm{inch}$, belt circumference length $=20.57$ inch, ratio gear box $=143$ $\mathrm{rpm}$, the result of the sieving tool rotational speed $=143 \mathrm{rpm}$

\section{Trial Processing Data}

In the process of testing the production of cassava flour, the following results were obtained:

Table 4.1: Trial Process Data

\begin{tabular}{|c|l|c|c|}
\hline Trial & Cassava Raw Material & Cassava Weight & Production Time \\
\hline 1 & Wet Cassava & $100 \mathrm{~kg}$ & 1 jam \\
\hline 2 & Dried Cassava & $50 \mathrm{~kg}$ & $40 \mathrm{jam}$ \\
\hline 3 & Cassava Flour & $30 \mathrm{~kg}$ & $1 \mathrm{jam}$ \\
\hline
\end{tabular}

\section{CONCLUSIONS}

The results of the designed cassava flour processing machine are considered adequate and able to facilitate human power in the processing of cassava flour which is still performed traditionally and takes a long duration of time. This traditional flour processing produces $40 \mathrm{~kg}$ of flour/day by the processes of peeling, grating, squeezing and sieving with a bamboo sieve.

The results of the processing of cassava with a harvesting age of 7 months, with the cassava in fresh, wet, peeled, washed conditions and chopped with a machine with a thickness of $2-3 \mathrm{~mm}$, the weight of cassava is $100 \mathrm{~kg}$. Cassava is dried under the sun for 4 - 5 days with 12-13\% remaining moisture content, making the weight of cassava reduced to $50 \mathrm{~kg}$. When dried cassava is processed into the flour with a machine of $5 \mathrm{~kg}$ filling capacity, the time required to produce powder is 10 minutes with a mesh size of 60 on the machine sieve. If the flour processing process is developed, the yield of cassava flour for 1 hour is $30 \mathrm{~kg}$.

\section{ACKNOWLEDGEMENTS}

Authors are grateful to Amamapare Polytechnic, Timika for providing financial assistance to carry out this research work and to Hasanuddin University Makassar for all of the academic support. .

\section{REFERENCES}

1. SulusiPrabawati,

NurRichanadan

Suismono.2011 Inovasipengolahansingkongmeningkatkanpendapatandandiversifikasipangan - Great Hall of Agricultural Research and PostHarvesting Development, Bogor Edition 4-10 May2011.email:bb_pascapanen@litbang.deptan.go.id

2. Eggeleston,G,Bokanga,M,Jean,Y.W,(1992) Traditional African mehods for Cassava processing and ulilisation and research needs.In M.O.Akrado and O.B Arene (Eds),Proceedings 4 thTrienialSimposium, International Society for rropical Root Crops-Africa Brancb,(pp.3-6) kinspinshase,2 aire, desember5-8,1989 
3. Sangoyomi, T. E., and A. Ayandiji. "Status of cassava production, distribution and utilization in Osun State, Nigeria." International Journal of Agricultural Science and Research (IJASR) 3.1 (2013): 1-5.

4. Prabu J.G Pandiangan.2017 Rancangbangnmesinpenggillingubipembuatgetukdenganselinderulirkapasitas $50 \quad \mathrm{~kg} / \mathrm{jam}$. Engineering Faculty, Industrial Technology Faculty, Medan. Emael : prabujg@gmail.com vol.3 no 2,November 2017:000-106

5. Yusuf, Asep, 2017. "RancangBangunMesinPengolahGonyong Multi Fungsi” Vol. 5 No., September 2017 Department of Agricultural Engineering and Biosystem, Postgraduate Prpogram of Padjadjaran University, approved: August 29, 2017. Email: asep.yusuf@unpad.ac.id.

6. Astuti, LudjiPantja. "Susceptibility of Four Rice Types to SitophilusoryzaeLinnaeus (Coleoptera: Curculionidae)." AGRIVITA, Journal of Agricultural Science 41.2 (2019): 277-283.

7. Daniel J. Fonseca, Gopal Uppal.,Timothy J. Greene A Knowledge-based system for conveyor equipment selection .Departmen of industrial Enginerng,The University of alabama, Tuscoloasa 3548t.USA EXPERT SYSTEM With Application 26 ( 2004) 615-625.

8. I.A.DanielJanuar 16-2014 Belt Conveyor System For Crushed Limestone Using 3 Roll Idlers.Departement of Machanical andMachatronisAfaBabolola University.

9. Akinlolu, Ajani R., et al. "Nutrient Compositions and Zinc-Bioavalability Estimation (In-Vitro) of the Edible Tropical Cereals." International Journal of Applied and Natural Sciences 3.5 (2014): 71-78.

10. O.M. Akusu.,J.O. Oyejide. 2018,Design and Construction of Dried Cassava Pellets Grinding Machine. (Department of Mechanical Engineering, Petroleum Training Institute (PTI), Effurun, Nigeria (Department of Mechanical Engineering,Federal University of Petroleum Resources, Effurun, Nigeria) Volume-7, Issue-3, pp-46-55 www.ajer.org

11. Erinofriardi,2012.Analisis KerjaBelt Conveor 5857-V Capacity 600 Tones/hour

12. Chakraborty, Samarpan, and DebabrataBasu. "HomesteadGardening: An Emerging Venture TowardsAchieving Food Security \&Nutritional Security-A Study of Selected Areas of West Bengal." International Journal of Applied and Natural Sciences (IJANS) ISSN (P) (2018): 2319-4014.

13. Sulistiawan, Herudkk, 2014. "RancanganMesinPengayakPasirCetak Vibrating Screen pada IKM Cor di JuwanaKabupatenPati” ISBN: 978-602-1180-04-4. Postgraduate Program of Mechanical Engineering, Engineering Faculty of University of Muria Kudus. E-mail: heru201155031@gmail.com

14. KristantoAgung,Pelmanto "PerancanganAlatPembuatTepung Cassava Yang ErgonomisMenggunakanPendekatanAntropometri” Industrial Engineering Faculty, University of Ahmad DahianYogyakarta.Email:agung kristanto@ie.uad.ac.id,ekopalmant@gmail.com

15. Suprapti Lies. M, 2005 TepungTapiokaPembuatan Dan Pemanfatannya.ISBN.979-21 0854-8.

16. Sularso. 2004. DasarPerencanaandan Pemilihan Elemen Mesin. Jakarta: PradnyaParamita

17. SonawanHery 2014 “Perancangan Elemen Mesin” ISBN : 978-602-8361-55-2 Second edition, March 2014 (Revised Edition), alvabeta, CV. Bandung Website : www.cvalfabeta.com

18. DahlanDahmir, 2012 “ElemenMesin” Citra Harta Prima Jakarta 2012 ISBN: 978-602-99040-1-7

19. A.Teddy Moch,2010. PerancanganMesinPembuatTepung Tapioca SingkongDengan 3 Tahapan Proses Kerja. University of MuhammadiyahJember. 
